\title{
Characterization of Serratia marcescens, S. liquefaciens, $S$. plymuthica and $S$. marinorubra by Electrophoresis of their Proteinases
}

\author{
By P. A. D. GRIMONT, FRANCINE GRIMONT AND \\ THE LATE H. L. C. DULONG DE ROSNAY \\ Laboratoire de Bactériologie, Université de Bordeaux II, \\ 3, place de la Victoire, 33000 Bordeaux, France
}

(Received 24 August 1976; revised 22 October 1976)

\section{SUMMARY}

Supernatant fluids from 5-day cultures in skim milk nutrient broth of 62 strains of Serratia marcescens, 24 of $S$. liquefaciens, 20 of $S$. plymuthica and 22 of $S$. marinorubra, together with 27 representative cultures of other genera, were submitted to agar gel electrophoresis. Proteinase activity was demonstrated by the casein-precipitating reaction. Serratia marcescens produced one to four cathodic proteinases and the patterns were in good accord with the classification of strains into biovars. Serratia liquefaciens often produced anodic and cathodic proteinases with differences between some biovars. Serratia plymuthica strains produced one common cathodic proteinase but no anodic proteinase. Each of the three biovars of $S$. marinorubra produced a specific proteinase. Other bacteria in the study (Erwinia carotovora, Erwinia chrysanthemi and Aeromonas hydrophila) produced proteinases that differed from the Serratia enzymes in their electrophoretic mobility. The results indicate that proteinase patterns could be useful in the identification of Serratia species and biovars.

\section{INTRODUCTION}

There have been several comparative studies of bacterial enzymes by zone electrophoresis for taxonomic purposes (e.g. Garber \& Rippon, 1968; Baptist, Shaw \& Mandel, 1969; Foissy, 1974; Gasser, 1970). However, in only a few of these studies (e.g. Hogan \& Colwell, 1969) were the findings compared with those obtained by numerical taxonomy.

Proteolytic activity has always been considered a key feature of the genus Serratia. It has been studied by several authors who assumed that there was only one enzyme (CastañedaAgulló, I956; McDonald \& Chambers, 1963). A single extracellular proteinase was purified by Miyata et al. (1970) and Rydén \& v. Hofsten (1968) found that a pigmented strain of Serratia produced one extracellular proteinase and several cell-bound peptidases.

A recent numerical taxonomic study (Grimont et al., 1977) delineated and described four species in the genus Serratia: S. marcescens, S. marinorubra, S. liquefaciens and S. plymuthica. Each of these species was composed of several biovars (subphenons). The objectives of the present work were to investigate proteinase heterogeneity in the genus Serratia and to attempt to correlate the results with those of the numerical taxonomic study. 


\section{METHODS}

Cultures. Sixty-two strains of $S$. marcescens, 24 of S. liquefaciens, 20 of S. plymuthica and 22 of $S$. marinorubra were studied, together with representatives of Enterobacter cloacae, Klebsiella mobilis, Erwinia carotovora, Erw. chrysanthemi, Erw. herbicola, Aeromonas hydrophila, and an unknown enterobacterium. The strains are listed in the study of Grimont et al. (1977).

Enzyme production. Skim milk nutrient broth [Liebig meat extract, $3 \mathrm{~g}$; Difco yeast

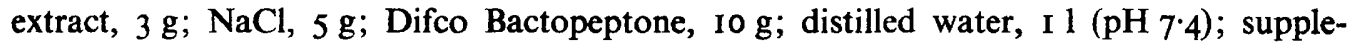
mented with $20 \%(\mathrm{v} / \mathrm{v})$ of a $20 \%(\mathrm{w} / \mathrm{v})$ skim milk solution] was dispensed into square flasks (10 $\mathrm{ml}$ per flask), inoculated from a $24 \mathrm{~h}$ culture in nutrient broth and incubated for 5 days at $30{ }^{\circ} \mathrm{C}$. Cultures were then centrifuged at $2000 \mathrm{~g}$ for ro min in a Beckman J2 I centrifuge. The supernatant fluid was separated and to this sodium ethylmercurithiosalicylate was added to give a final concentration of $0.0 \mathrm{\%} \%(\mathrm{w} / \mathrm{v})$. All treated supernatant fluids kept well for at least I week at $4{ }^{\circ} \mathrm{C}$.

Electrophoresis of proteinases. Difco Noble agar [60 ml; $1 \%(\mathrm{w} / \mathrm{v})$ in $0.05 \mathrm{M}$-Tris/maleic acid buffer, $\mathrm{pH} \mathrm{5.6]} \mathrm{was} \mathrm{poured} \mathrm{on} \mathrm{to} \mathrm{a} 18 \times 24 \mathrm{~cm}$ glass plate. The enzyme solutions (I0 to I $5 \mu$ l) were applied in circular wells $(2.5 \mathrm{~mm}$ diam.) cut in the gel. Sixteen samples, including six replicates of a reference sample, could be processed at the same time. Tanks contained $0.05 \mathrm{M}$-Tris/maleic acid buffer, $\mathrm{pH} 5.6$, and voltage was applied at $5 \mathrm{~V} \mathrm{~cm}^{-1}$ for $10 \mathrm{~h}$. Heating was prevented by packing ice on and under the apparatus. At mid-run, the ice was renewed and the buffer solutions in the anodic and cathodic tanks were mixed to equilibrate the pH. Elphor apparatus (Elphor, Munich, Germany) was used for electrophoresis with a power supply from APELAB (Bagneux, France).

Demonstration of proteolytic activity. Proteinase activity was demonstrated by pouring $40 \mathrm{ml}$ of molten casein agar gel $[0.7 \%(\mathrm{w} / \mathrm{v})$ agar $(\mathrm{BBL}), \mathrm{r} \%(\mathrm{w} / \mathrm{v})$ sodium caseinate (General Biochemicals, Ohio, U.S.A.), $0.004 \mathrm{M}-\mathrm{MgCl}_{2}, 0.0 \mathrm{I} \%$ ethylmercurithiosalicylate, and $0.05 \mathrm{M}$ Tris/maleic acid buffer, $\mathrm{pH}$ 6.2] on the electrophoresis gel after completion of electrophoresis (Dahle, 1970). Plates were incubated overnight at $37^{\circ} \mathrm{C}$ in a moist chamber, and then examined for white spots of precipitated paracaseins. Faint additional spots appeared after 2 days. Serratia liquefaciens 507 (СCM400) was used as a reference strain because preliminary experiments showed that it gave both cathodic and anodic spots. The distance of migration of the cathodic proteinase of strain 507 was assigned a value of I cathodic unit (c.u.). The distance of migration of other cathodic proteinases were expressed relative to this value. The anodic proteinase of strain 507 also served as a reference for anodic proteinases (I anodic unit, a.u.). All experiments were performed at least twice.

When mean migration values are given for a group of proteinases, the associated standard deviation value is the square root of total variance. Total variance was calculated as the sum of pooled within-strain variance and between-strain variance.

Bacterial methods. These were described by Grimont et al. (1977).

\section{RESULTS}

In $91.7 \%$ of the strains examined, presence (or absence) of casein-precipitating enzymes was consistent with positive (or negative) results for both tube gelatin liquefaction and the plate test for gelatin hydrolysis (Table $\mathrm{r}$ ). In the latter method hydrolysis was detected by flooding plates with $10 \%(\mathrm{w} / \mathrm{v})$ aqueous mercuric chloride.

Of the strains examined for electrophoretic proteinase patterns (see Figs I and 2), the 
Table I. Correlation between gelatin hydrolysis and the presence of casein-precipitating enzyme(s) in Serratia and related organisms

$\begin{array}{cccc}\overbrace{\text { Tube method }}^{\text {Gelatin hydrolysis* }} & \begin{array}{c}\text { Casein- } \\ \text { precipitating } \\ \text { enzymes }\end{array} & \begin{array}{r}\text { No. of } \\ \text { strains }\end{array} \\ + & \text { Plate method } & + & \mathbf{1 2 3} \\ 0 & + & 0 & 20 \\ + & 0 & 0 & 8 \\ 0 & + & \text { Faint spot } & 2 \\ 0 & 0 & \text { Faint spot } & 2 \\ + & + & 0 & 1\end{array}$

* Methods described in Grimont et al. (1977): +, positive reaction; o, negative reaction.

following showed no casein-precipitating activity and are not included in the Figures: 284, 259, 258 (phenon A); 239, 280, 27I (phenon $\mathrm{CI}_{\text {) }}$; 34, 273, 5I 7, 5I2 (phenon C2); 294 (phenon B); 38; E20, EI 5, EI6 (phenon D); E62, E63, CI, C4, C3, C5 (phenon E); E29, E34, E33, E27 (phenon F); AI, A5, A3, A4 (phenon G). Mean values, plus and minus one standard deviation, of relative migration rates are shown in Figs $I$ and 2. One anodic unit (a.u.) was found to correspond to $-0.36 \mathrm{c.u}$. (average of 63 measurements). This averaged value was used to convert anodic units to cathodic units for determination of standard deviations when the same slowly migrating spot was found on either the cathodic or the anodic side. Sometimes what was considered to be one spot in one experiment appeared as a double spot in a replicate experiment; in these cases, both results are shown.

When incubation of the indicator gel was prolonged by I day, the centre of the large spots became transparent as hydrolysis progressed. On prolonged incubation, other faint spots sometimes appeared (open circles in Figs $I$ and 2), but these varied between experiments.

For the purposes of presentation, mean relative migration rates were grouped into classes for each of the four Serratia species and are shown as histograms in Fig. 3. The peaks in all four histograms were labelled by a single system (PI to PII).

\section{Serratia marcescens}

Strains of $S$. marcescens produced one to four proteinases (Fig. I). The relative migration rate of one of these proteinases could not be measured as the casein precipitation began in the sample well and progressed toward the 0.20 to $0.30 \mathrm{c}$.u. region on the cathodic side. Such complex proteinases are referred to hereafter as $\mathrm{P}(5)$ proteinase. A histogram of mean relative migration rates is shown in Fig. $3(a)$ : this does not include the occasional double spots. Proteinases were distributed among four peaks labelled P6, $\mathrm{P}_{7}, \mathrm{P}_{9}$ and $\mathrm{PI}_{1}$. Peak 9 was wide ( 0.70 to $\mathrm{I} \cdot 05 \mathrm{c}$.u.) and could be partitioned into two different proteinases: P9a (mean migration 0.80 c.u.) and Pgb (mean migration 0.89 c.u.).

Proteinase patterns were compared within and between the Serratia marcescens biovars described by Grimont et al. (1977). Biovar AI. All strains produced proteinase P6. The seven strains which could utilize DL-carnitine as sole carbon source produced proteinase P9a. The other two strains (DL-carnitine negative) produced proteinase P9b. The DL-carnitine positive strains of this group are designated biovar Ara, and the others biovar Arb. Relative migration rates of proteinase $\mathrm{P9a}$ were significantly different from those of proteinase $\mathrm{Pg}$ b in group Ar $(P<0.05)$. Biovar $A 2$. All strains (except one) produced two proteinases: $P_{7}$ and P9b. Strain 449 produced proteinase $\mathrm{P}_{7}$ and an aberrant spot in the $0.75 \mathrm{c}$.u. region. Biovar A3. This biovar appeared somewhat heterogeneous with respect to proteinase patterns. 


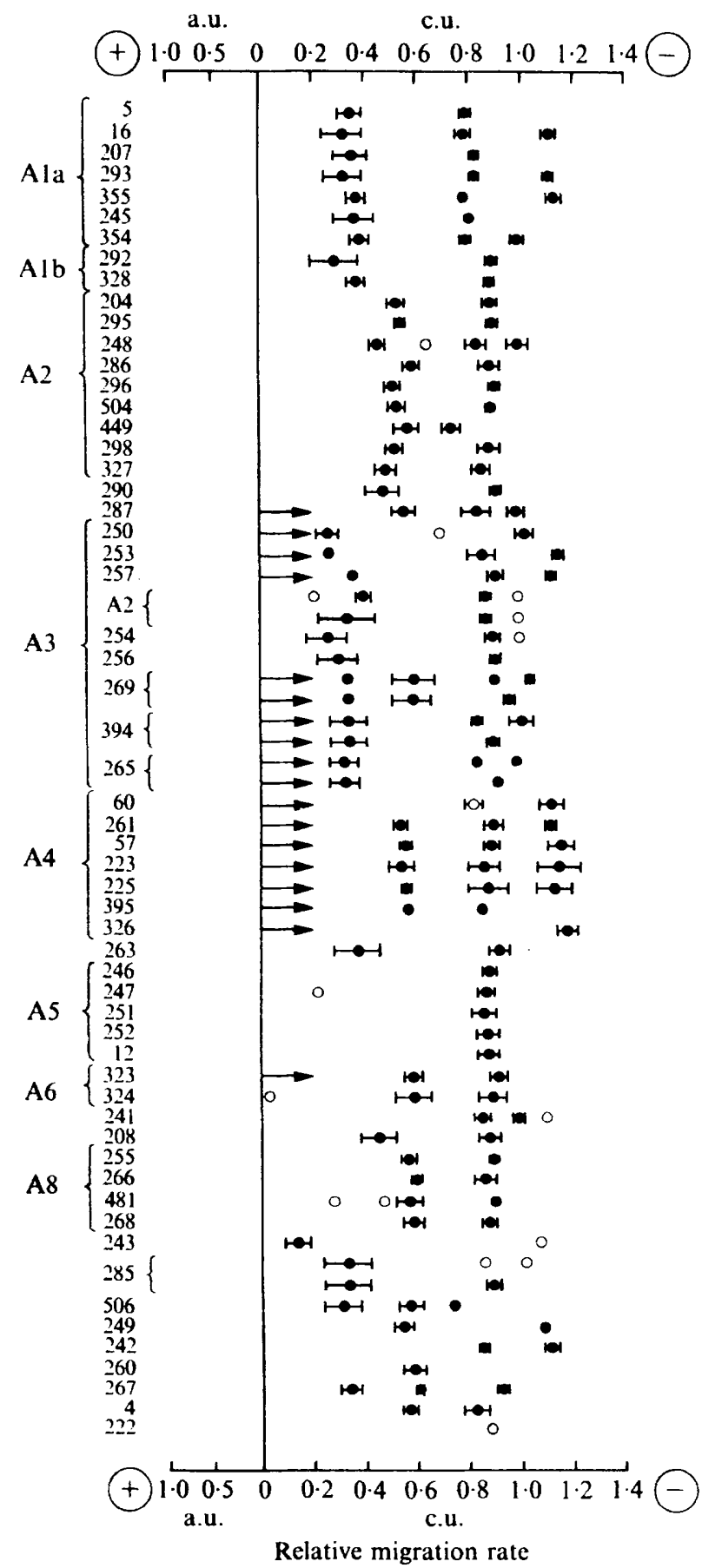

Fig. I. Mean values and standard deviations of relative migration rates of $S$. marcescens proteinases. The cathodic proteinase of $S$. liquefaciens strain 507 was used as the reference for migration rate measurements and was given the value of $I$. Strains are listed in the order in which they were grouped in Fig. 1 of the study of Grimont et al. (1977). Strains that did not show casein-precipitating activity have been omitted. Both patterns are given for strains that occasionally showed double spots. Faint spots are indicated by $O$. Complex $P(5)$ proteinases are indicated by an arrow starting from the zero line. 


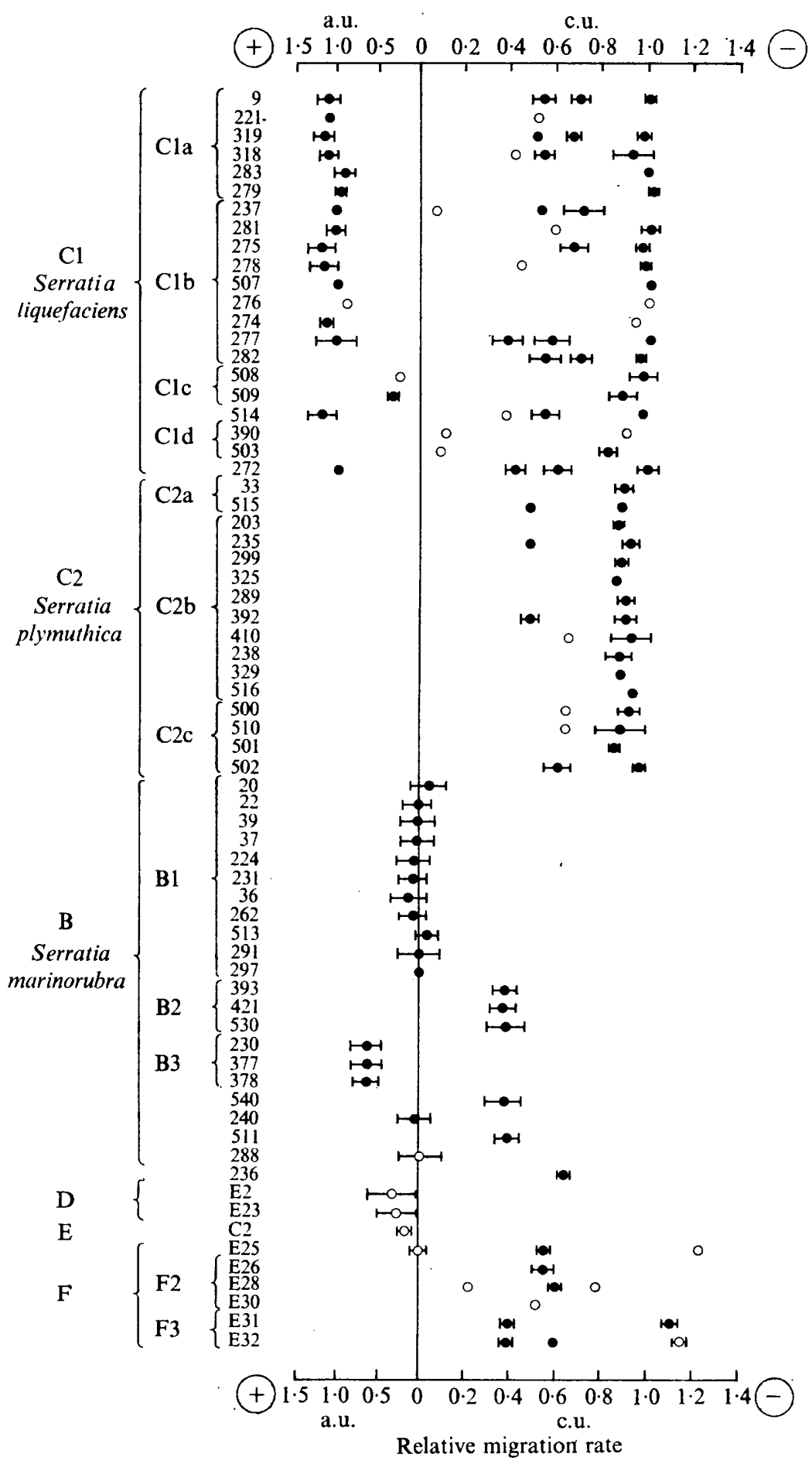

Fig. 2. Mean values and standard deviations of relative migration rates of proteinases produced by $S$. liquefaciens, $S$. plymuthica, $S$. marinorubra and some other bacteria. Phenon D contains Erwinia herbicola; phenon F 'pectobacteria'; subphenon $\mathrm{F}_{2}$ Erwinia carotovora; and subphenon $\mathrm{F}_{3}$ Erwinia chrysanthemi. Strain C2 is a yellow-pigmented Enterobacter cloacae and strain 236 is Aeromonas hydrophila. Migration rates are expressed relative to the position of the cathodic proteinase spot of strain 507. Strains are listed in the order in which they were grouped on Fig. I of the study of Grimont et al. (1977). Strains that did not show casein-precipitating activity have been omitted. 


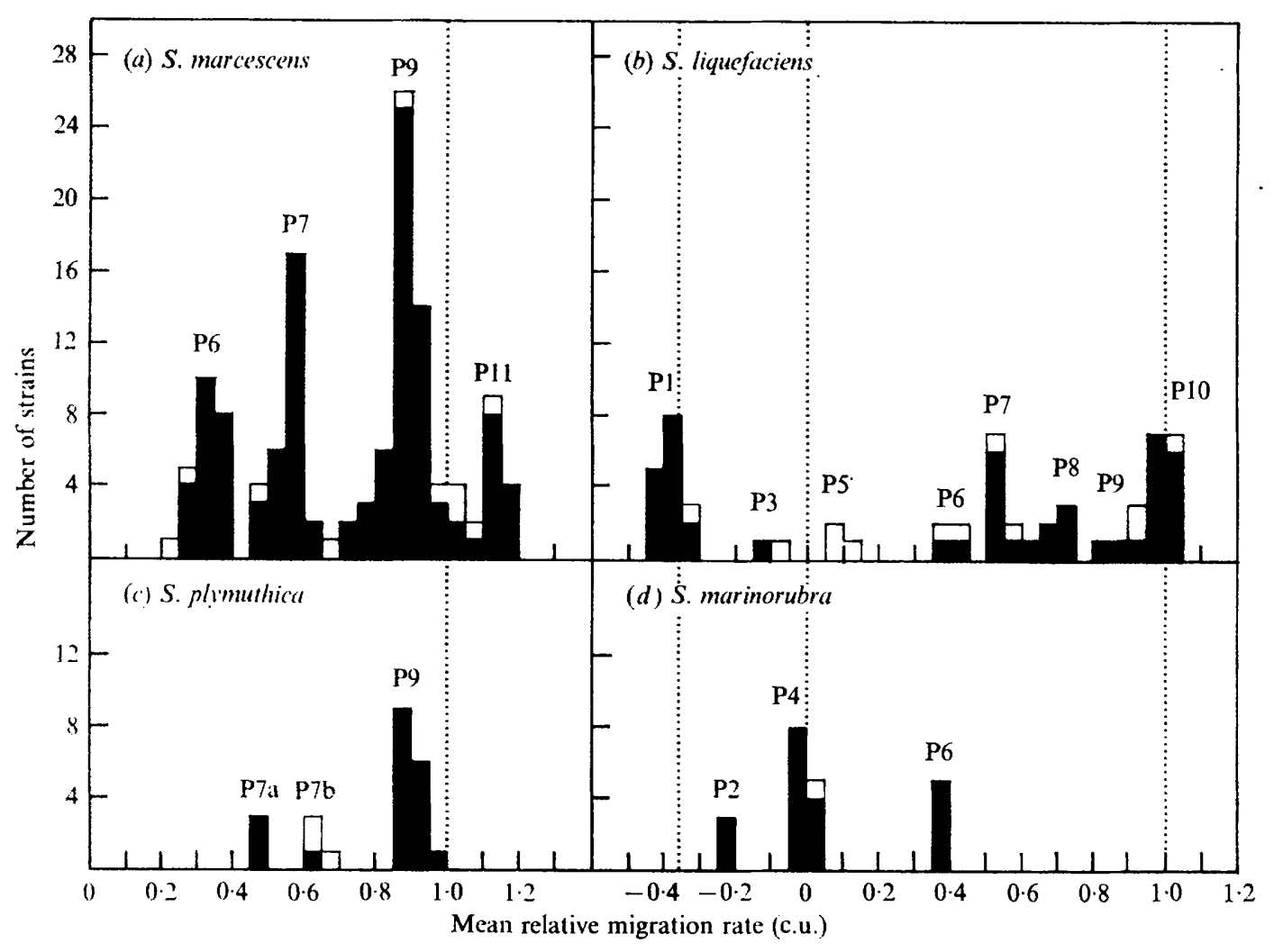

Fig. 3. Histograms summarizing data from Figs 1 and 2. Mean values of relative migration rates of proteinases were grouped into classes of 0.05 c.u. (abscissa). Ordinates indicate the number of strains giving a spot in that position. Histograms excluding faint spots are shown in black; the largest contours include faint spots. Dotted lines indicate the zero line, I c.u. line, and I a.u. $(=-0.36$ c.u. $)$ line.

Table 2. Mean values and standard deviations of relative migration rates of the different proteinases of each Serratia marcescens biovar

Values for proteinases produced by a minority of strains in a biovar are given in parentheses. Faint spots and occasional double spots are omitted for clarity. $\mathrm{P}(5)$ is a slow migrating, tailing proteinase and its rate of migration could not be measured.

Cathodic proteinases

$\begin{array}{lcccccc}\text { Biovar* } & \text { P(5) } & \text { P6 } & \text { P7 } & \text { P9a } & \text { P9b } & \text { PII } \\ \text { A1a } & & 0.36 \pm 0.07 \mathrm{I} & & 0.81 \pm 0.026 & & (1 \cdot 13 \pm 0.032) \\ \text { A1b } & & 0.34 \pm 0.082 & & & 0.89 \pm 0.025 & \\ \text { A2 } & & & 0.53 \pm 0.045 & & 0.89 \pm 0.036 & \\ \text { A3 } & + & 0.31 \pm 0.081 & (0.59 \pm 0.085) & & 0.91 \pm 0.050 & (1 \cdot 14 \pm 0.030) \\ \text { A4 } & + & & 0.55 \pm 0.034 & & 0.88 \pm 0.058 & 1 \cdot 14 \pm 0.061 \\ \text { A5 } & & & & & 0.87 \pm 0.044 & \\ \text { A6 } & + & & 0.59 \pm 0.054 & & 0.91 \pm 0.051 & \\ \text { A8 } & & & 0.58 \pm 0.039 & & 0.89 \pm 0.031 & \end{array}$

* See Grimont et al. (1977). 
Table 3. Mean values and standard deviations of relative migration rates of the different proteinases of each Serratia liquefaciens biovar

Values for proteinases (cathodic) produced by a minority of strains in a biovar are given in parentheses. For anodic proteinases, relative migration rates are given in both a.u. and c.u.

\begin{tabular}{|c|c|c|c|c|c|c|c|c|}
\hline \multirow[b]{2}{*}{ Biovar* } & \multicolumn{2}{|c|}{ Anodic proteinases } & \multicolumn{6}{|c|}{ Cathodic proteinases } \\
\hline & PI & $\mathbf{P}_{3}$ & $\mathrm{P}_{5}$ & P6 & P7 & P8 & $\mathrm{P}_{9}$ & Pio \\
\hline Cia & $\begin{array}{c}\text { I.06 a.u. } \\
\pm 0.153 \\
\text { [or }-0.38 \text { c.u. } \\
\pm 0.055]\end{array}$ & & & $\dagger$ & $\begin{array}{l}0.52 \text { c.u. } \\
\pm 0.044\end{array}$ & $\begin{array}{r}(0.68 \text { c.u. } \\
\pm 0.047)\end{array}$ & & $\begin{array}{l}0.99 \text { c.u } \\
\pm 0.066\end{array}$ \\
\hline $\mathrm{CIb}$ & $\begin{array}{c}\text { I.06 a.u. } \\
\pm 0.201 \\
\text { [or }=0.38 \mathrm{c.u} . \\
\pm 0.072]\end{array}$ & & $\ddagger$ & $\begin{array}{l}(0.4 \mathrm{I} \text { c.u. } \\
\pm 0.086)\end{array}$ & $\begin{array}{l}0.56 \mathrm{c.u} \\
\pm 0.074\end{array}$ & $\begin{array}{r}\text { (0.69 c.u. } \\
\pm 0.072)\end{array}$ & & $\begin{array}{l}0.99 \text { c.u. } \\
\pm 0.034\end{array}$ \\
\hline Cic & & $\begin{array}{c}0.29 \text { a.u. } \\
\pm 0.096 \\
\text { [or }=0.10 \text { c.u. } \\
\pm 0.034]\end{array}$ & & & & & $\begin{array}{l}0.92 \text { c.u. } \\
\pm 0.072\end{array}$ & \\
\hline Cid & & & $\begin{array}{c}0.10 \mathrm{c.u} . \\
\pm 0.014 \\
\text { (faint) }\end{array}$ & & & & $\begin{array}{l}0.86 \text { c.u. } \\
\pm 0.067\end{array}$ & \\
\hline
\end{tabular}

* See Grimont et al. (1977).

† A faint spot with a relative migration rate of 0.42 c.u. appeared in one experiment with one strain.

$\ddagger$ A faint spot with a relative migration rate of 0.07 c.u. appeared in one experiment with one strain.

Pattern [P(5), P6, P9b, PI I] was given by four strains, pattern [P6, P9b] was given by three strains, and pattern $\left[\mathrm{P}(5), \mathrm{P} 6, \mathrm{P}_{7}, \mathrm{P} 9 \mathrm{~b}\right]$ by one strain. Strain 250 produced proteinases $\mathrm{P}(5)$ and $\mathrm{P} 6$ and two aberrant spots. Biovar $A 4$. This biovar was characterized by the $\left[\mathrm{P}(5), \mathrm{P}_{7}\right.$, Pgb, PII] pattern, although some strains lacked one or two of the proteinases. Biovar A5. This biovar produced one spot (Pgb) with a marked tail in the 0.75 c.u. region. Biovar A6. Both strains had a $[\mathrm{P}(5), \mathrm{P} 7, \mathrm{P} 9 \mathrm{~b}]$ pattern. Biovar A8. All four strains had the proteinase pattern $\left[\mathrm{P}_{7}, \mathrm{P} 9 \mathrm{~b}\right]$ which was indistinguishable from the proteinase pattern of biovar A2.

Mean relative migration rates with standard deviations are given for each biovar in Table 2.

Serratia marcescens S29 (NRC7021, received from Dr R. Latta), whose proteinase has been studied by McDonald \& Chambers (1963), was also included in this study. It was found to belong to $S$. marcescens biovar A2 using the key characters of Grimont et al. (1977), which is in accord with the presence of proteinases $\mathrm{P}_{7}$ and $\mathrm{P} 9 \mathrm{~b}$.

\section{Serratia liquefaciens}

Of the eight different proteinase spots in strains of $S$. liquefaciens, two migrated anodically, $\mathrm{PI}_{\mathrm{I}}$ and $\mathrm{P}_{3}$, and six migrated cathodically, $\mathrm{P}_{5}, \mathrm{P} 6, \mathrm{P}_{7}, \mathrm{P} 8, \mathrm{P}_{9}$ and Pro (Fig. $3 b$ ). Table 3 summarizes the mean and standard deviations of the relative migration rates according to biovars.

Biovars Cra and $\mathrm{Cr}$ b of $S$. liquefaciens could not be distinguished from each other by proteinase patterns as they shared a characteristic common pattern [PI, Pro]. Strain 280 (received from Professor Le Minor) was allegedly descended from CDCi284-57, the proposed neotype of S. liquefaciens (Ewing et al., 1973). Unfortunately, this culture did not produce a casein-precipitating enzyme but another culture of strain CDCI284-57, received 
Table 4. Mean values and standard deviations of relative migration rates of the different proteinases of each Serratia plymuthica biovar

Values for proteinases produced by a minority of strains in a biovar are given in parentheses.

\begin{tabular}{cccc} 
& \multicolumn{3}{c}{ Cathodic proteinases } \\
Biovar* & $\overbrace{\text { P7a }}$ & P7b & P9b \\
C2a & $(0.48 \pm 0)$ & & $0.89 \pm 0.032$ \\
C2b & $(0.48 \pm 0.033)$ & $\dagger$ & $0.89 \pm 0.048$ \\
C2c & & $(0.63 \pm 0.068)$ & $0.90 \pm 0.084$
\end{tabular}

* See Grimont et al. (1977).

† A faint spot with a relative migration rate of $0.65 \mathrm{c} . \mathrm{u}$. appeared in one experiment with one strain.

Table 5. Mean values and standard deviations of relative migration rates of the different proteinases of each Serratia marinorubra biovar

For anodic proteinases, relative migration rates are given in both a.u. and c.u.

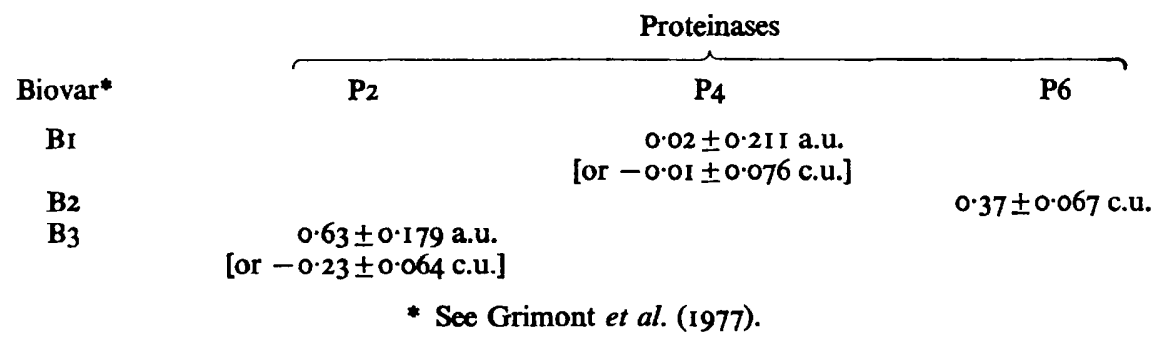

directly from the Center for Disease Control (Atlanta, Georgia, U.S.A.) produced proteinases $\mathrm{PI}$ and Pro as expected. However, the type strain of $S$. liquefaciens (ATCC14460, Sneath \& Skerman, 1966; 503 of this study) produced a peculiar set of proteinases [P5, P9], consistent with its affiliation to biovar $\mathrm{CId}$, and not inconsistent with its designation as the type strain of this species.

\section{Serratia plymuthica}

The histogram (Fig. $3 c$ ) indicates three proteinases, $\mathrm{P}_{7} \mathrm{a}, \mathrm{P}_{7} \mathrm{~b}$ and $\mathrm{P} 9$, in $S$. plymuthica. Proteinase P9 was produced by all strains of this species and there was no significant difference between the biovars (Table 4).

When supernatant fluids from cultures of $S$. plymuthica and $S$. liquefaciens were run on the same plate, the migration rates of the P9 spots were consistently lower than those of the Pro spots.

\section{Serratia marinorubra}

Serratia marinorubra has three different proteinases, P2, P4 and P6 (Fig. $3 d$ ). Each corresponds to a specific biovar (Table 5). Strains 240 and 288 , which produced proteinase $\mathbf{P}_{2}$, shared the biochemical characteristics of biovar BI (see Table 4, Grimont et al., 1977). Strains 540 and $5 \mathrm{II}$, which produced proteinase $\mathrm{P}_{4}$, shared the characteristics of biovar B2. The proteinase of the proposed neotype for $S$. rubidaea (Ewing et al., 1973) was also typical of biovar B2. 


\section{Other genera}

Of the other strains studied (see Table I, Grimont et al., 1977), only strains of Erwinia carotovora (but not Erw. carotovora var. atroseptica), Erwinia chrysanthemi and the single strain of Aeromonas hydrophila produced enzyme(s) that unequivocally precipitated casein. Some strains of Erwinia herbicola and a yellow-pigmented strain of Enterobacter cloacae sometimes showed a faint proteinase spot. The relative migration rates of these proteinase spots were distinguishable from those of Serratia species (Fig. 2).

\section{DISCUSSION}

Previous reports on the proteinase activity of the genus Serratia indicated the existence of only one enzyme (McDonald \& Chambers, 1963; Miyata et al., 1970). However, the results of our electrophoretic studies showed a high degree of heterogeneity, which correlated well with the results of the numerical taxonomic study of Grimont et al. (1977).

At the species level, proteinase patterns are remarkably consistent and strains which grouped in the same biovar generally displayed similar proteinase patterns. This supports the idea that some of the biovars represent valid taxa of low rank (Grimont et al., 1977). However, some strains of biovar A3 gave proteinase patterns identical with that of biovar AIb [P6, P9b]; and biovar A2 could not be distinguished from biovar A8 using proteinase patterns alone. Both $S$. marcescens and $S$. plymuthica produced proteinase $\mathrm{P}_{9}$; and proteinase P6 was produced by some strains of $S$. marcescens, S. liquefaciens and $S$. marinorubra. It should be stressed that similar migration rates do not necessarily imply that the proteinases are identical. Only differences in proteinase patterns may be significant, especially when different species are compared.

Some Serratia strains were not classified into subphenons (biovars) by computer analysis (Grimont et al., 1977). Possible reasons for this are: (i) a strain may differ from a group only in vigour (as defined by Sneath, I968); (ii) a strain while giving typical results with tests that were selected for identification purposes, gave unusual results with other tests; (iii) a strain could be a single representative of a new biovar. Proteinase patterns may help in assigning a strain to a biovar. A good example is that of certain strains of $S$. marinorubra $(240,288$, 5 II and 540). These did not group with any subphenon but could be identified as members of biovars BI or B2 on the basis of selected identification characters. Their proteinase patterns were in good accord with this identification.

The use of epidemiological markers for the genus Serratia (i.e. serotyping; phage typing; typing by production of, or sensitivity to, bacteriocins) is limited to a few laboratories in the world due to the unavailability of commercial sera and to the lack of standardization of the other methods. Determination of biovars by proteinase patterns, although probably not as finely divisive as the aforementioned methods, could be performed in any laboratory with simple equipment and is currently used in our laboratory.

Thanks are due to Professor P. du Pasquier for hospitality and to Professor P. H. A. Sneath and Professor M. P. Starr for helpful comments. 


\section{REFERENCES}

BAPTIST, J. N., SHAW, C. R. \& MANDEL, M. (1969). Zone electrophoresis of enzymes in bacterial taxonomy. Journal of Bacteriology 99, $180-188$.

CAstañeda-Agulló M. (1956). Studies on the biosynthesis of extracellular proteases by bacteria. I. Serratia marcescens. Synthetic and gelatin media. Journal of General Physiology 39, 369-375.

D AHLE, H. K. (1970). Zymograms in agar gel of some animal and bacterial proteinases. Acta pathologica et microbiologica scandinavica $\mathrm{B} 78,575-578$.

EwING, W. H., DAvis, B. R., FIFE, M. A. \& Lessel, E. F. (1973). Biochemical characterization of Serratia liquefaciens (Grimes and Hennerty) Bascomb et al. (formerly Enterobacter liquefaciens) and Serratia rubidaea (Stapp) comb. nov. and designation of type and neotype strains. International Journal of Systematic Bacteriology 23, 217-225.

Forssy, H. (1974). Examination of Brevibacterium linens by an electrophoretic zymogram technique. Journal of General Microbiology 80, 197-207.

GaRber, E. D. \& RIPPON, J. W. (1968). Proteins and enzymes as taxonomic tools. Advances in Applied Microbiology 10, I37-139.

GASSER, F. (1970). Electrophoretic characterization of lactic dehydrogenases in the genus Lactobacillus. Journal of General Microbiology 62, 223-239.

Grimont, P. A. D., Grimont, F., Dulong de Rosnay, H. L. C. \& Sneath, P. H. A. (1977). Taxonomy of the genus Serratia. Journal of General Microbiology 98, 39-66.

Hogan, M. A. \& ColwEll, R. R. (I969). DNA base composition and esterase patterns of bacteria isolated from deep sea sediments. Journal of Applied Bacteriology 32, 103-I I I.

MCDONALD, I. J. \& ChAMBERs, A. K. (I963). Some characteristics of proteinases of an obligately psychrophilic red pigmented bacterium and of Serratia marcescens. Canadian Journal of Microbiology 9, 871877.

MiYata, K., Maesima, K., Tomoda, K. \& Isono, M. (1970). Serratia protease. I. Purification and general properties of the enzyme. Agricultural and Biological Chemistry 34, 310-318.

RYDÉN, A. C. \& v. HorsteN, B. (1968). Some properties of the extracellular proteinase and the cell-bound peptidase of Serratia. Acta chemica scandinavica 22, 2803-2808.

SNEATH, P. H. A. (1968). Vigour and pattern in taxonomy. Journal of General Microbiology 54, I-II.

SNEATH, P. H. A. \& Skerman, V. B. D. (1966). A list of type and reference strains of bacteria. International Journal of Systematic Bacteriology 16, I-I 33. 